\title{
Black Women in Computing and Technology: Identity affirmation and Resistance
}

\author{
Mory Márcia de Oliveira Lobo \\ UFMT, Education Institute, 78068-600 \\ Cuiabá, Brazil, \\ moryprofessora@hotmail.com
}

\author{
Karen da Silva Figueiredo Medeiros Ribeiro \\ UFMT, Education Institute \& Computer Science Institute, 78068-600 \\ Cuiabá, Brazil, \\ karen@ic.ufmt.br \\ and \\ Cristiano Maciel \\ UFMT, Education Institute \& Computer Science Institute, 78068-600 \\ Cuiabá, Brazil, \\ cmaciel@ufmt.br
}

\begin{abstract}
Considering black women in Brazil as a research subject involves new challenges about topics that are increasingly complex. In this sense, pertinent questions arise in seeking to comprehend contemporary phenomena and, consequently, leave room for disputable formulations, especially in areas of which science and technology have little understanding. This article offers a bibliographical essay that aims to begin the path to include black women in computing and technology, in a social background of sexism and racial segregation. Furthermore, it presents a summary of the resistance strategies used in black women's course in this area by analyzing the elements of black identity strengthened by these initiatives in Brazil and abroad.
\end{abstract}

Keywords: black identity, black women and technology, black women and computing, diversity, computer science.

\section{Introduction}

The current social configuration of the 21st Century stems from consequential historical transformations and expressive changes in contemporary women's social behavior. The cybernetic era, engulfed by post-industrial capitalism, stimulates excessive consumption that marks the passage of a producerist society to a consumerist society [1].

The so-called information society brought about structural disruptions that also characterized behavioral changes in the relations of knowledge and technology production, assigning new meaning to the roles played by subjects in this process. Thus, some fields of knowledge were attributed to a masculine domain, as was the case of computing, which is a field historically dominated by white men [2]. 
Despite the fact that women, as members of contemporary society, are consuming technology on a daily basis, it is possible to observe that they were restricted from the course of technological production. Women represent less than $20 \%$ of workers in the field, only a third of whom are black [3].

Considering the black woman as a research object means undertaking new challenges related to increasingly complex issues. Questions arise on issues that are crucial for understanding contemporary phenomena and, consequently, produce formulations that are open to the challenges, mainly in areas that are still unfamiliar to fields of science and technology. In this sense, this article aims to: (i) offer a bibliographic essay on incorporating black women in fields of computing and technology, and (ii) create a summary of resistance strategies developed by black women in this area while analyzing elements of black identity reinforced by these initiatives, in Brazil and abroad, using the contribution of Netnography and Discourse Analysis. Considering the studies undertaken, we also seek to understand the initiatives in Computer Science and Technologies that contribute to the discussion of racial issues in Brazil as a form of social resistance.

This article is an extension of the first study conducted in [4]. After this introduction, the rest of this article is organized as follows: the second section discusses theoretical perspectives on the black and female identity and the historical relationship with the field of technology; the third section presents actual cases of resistance strategies employed by black women in the field of computer science and technology in Brazil and abroad; lastly, the fourth section concludes with final considerations.

\section{Theoretical Perspectives}

\subsection{Identity of Black Women}

According to Silva [5], gender studies addressing female and black identity have grown in number and delved into historical factors, which are crucial for understanding identity building and for establishing citizenship rights. Criticism against capitalist society and mass culture implies gender issues and leads us to the following question: how does the black woman, within the context of social segregation, reach technological production?

This is undoubtedly an important issue to explore when attempting to understand black women's movement in certain spaces by addressing identity, especially considering that, in Brazil, due to its harrowing experience with slavery and, subsequently, the influence of the "population whitening" ideology. As stated by the sociological and political reading of the whitening ideology [6], blacks are encouraged to breed with whites and thus eliminate their existence through cultural and social incorporation of whiteness. There was an expressive fragmentation of this black identity based on the consumption of new technology, while very little was expected of blacks as technology producers.

As said by Stone [7], identity is the means through which individuals reveal themselves to others. In Gomes' approach [8], identity is a response to society about oneself based on an attitude of belonging, appreciation, and affirmation. The individual recognizes herself based on multiple social identities with countless variables, and on how she views herself based on her relationship with others. Identity is able to shift codes and incorporate behaviors and cultural complexities in its exercise of construction and exchange.

These codes can be incorporated and established by the process of acculturation and can thus promote conduct that arises from a mentality favored in the image one has of oneself. In the sense of psychological structure, experiencing a shift in course may fragment that identity.

Considering the complexities and singularities that black women experience in the process of social integration, the question remains: which feelings are foreign to their physical nature, insofar as their values are different and have been disregarded through the imposition of racial and male hegemony characterized by the dominance of the white stereotype?

Perhaps the greatest challenge is attempting to understand the world of vertical reference created by a set of values, in view of the polysemy of its own subjectivity. In this process, we are likely to observe the gregarious nature of human relationships, sharing existential complexities, and implicating difficult positioning of diversity in the technology field. This coexistence involves one of the present challenges in diverse societies [9].

The stereotypical image of the black woman is still found in a circumstantial set of habits and customs that are foreign to her in the way they are socially imposed, thus contributing to a possible identity fragmentation. The monocultural academic space that still insists on the invisibility of diversity marginalizes the existential complexity of cultural universes that escape its reference.

Thus, it can be observed that an irrefutable existential crisis occurs in this process due to the increasing imposition of social patterns that are out of context regarding these women's reality. This creates the need for image 
reconstruction of assertion given by the exhaustion of the mechanism of racial domination and sexism, which encounters resistance in the efforts in favor of spherical relations, contemplated in the battle towards respect for diversity.

In this sense, observing the path followed by black women in the fields of computer science and technology leads to important discoveries in scientific research, insofar as this path identifies forms of resistance and instrumental phenomena to confront a possible change of scenery in a space occupied by white males in a country that, according to the IPEA institute (Instituto de Pesquisa Econômica Aplicada) [10], is considered the second largest black nation in the world, second only to Nigeria.

Discussing women of color undertaking scientific research and considering the conjunctures that are subjectively attributed to them in a historical, social, economic and cultural context, leads us to reflect and question the arduous coexistence of stratified societies, considering all the complexities and singularities that have been disregarded by the hegemony of a chauvinist/racist culture and by the domination of an entire system that is not tailored for a person of color.

The first major challenge would be identifying important circumstances regarding the history of women in computing, starting with the quest for self-affirmation in the field of exact sciences, by analyzing initiatives considering the aforementioned history of fragmentation [11].

The course of this study is traversed by different scientific areas, such as history, sociology, anthropology, psychology, education and computer science, while seeking to understand the processes of black women's image construction and its psychological and social consequences. Computing is used as the main research field as a space of considerable fragmentation of the presence of black women.

The French author and psychiatrist Frantz Fanon [12] formulated a subjective analysis of the woman of color in his studies. Fanon's book "Black Skin, White Masks" devoted a whole chapter to studying how subjective processes built throughout history influenced the black woman's perception of self, leaving what the author names Weltanschauung scars.

Based on this concept, the author defines an important trait in the behavior and discourse of the black women he researched, considering the image projected from the unfolding of colonization to eugenic ideals that resulted in racism. The author reiterates that it is possible to locate the root of inauthenticity in the image of the black woman; i.e., there is no authenticity of self-reflected in the mirror, as she is mobilized by unconscious conflicts that may be related to identity formation.

There is an unconscious inferiority complex which, if not overcome, will never arrive at the authentic image insofar as the "place" to which it belongs begins a dialectical discussion on "to be" and "to have", as that artificiality prevents her from re-shifting the world view on Africanness.

The American researcher Bell Hooks [13] also questions this identity formation when mentioning the obliteration of the black female presence in academic circles when observing a timid posture on this matter. The author emphasizes the ambivalent attitudes of feminist black women facing the discursive forms of power that determine what she will call "points of view" and politics. Thus, she questions this behavior as a latent issue that should be contemplated in the academic context of female blackness.

The IPEA report [10] that maps the living conditions of black women in Brazil, from 2011 to 2016, presents important results for the current investigation since it maintains a dialogue with the issues raised by Fanon and Hooks regarding the dominant reality in Brazil.

It is important to examine and question this topic through an investigative logic of socio-economic-cultural indicators, as well as through standpoints assumed by subjective segmentation and psychological factors that acquire consistency to the extent that the conditions of the identity building of black women appear in the struggle for breaking into new technologies.

Brazilian theorist Nilma Lino Gomes [8] addresses black identity and conducts research in the field of education on the context of racial relations in Brazil. Gomes' studies reiterate that identity is a response given to society about oneself, bearing an attitude of belonging, appreciation and affirmation. The individual recognizes herself through multiple social identities and countless variables and how she views herself based on her relationship with others. In this exchange, building an identity means shifting codes and incorporating behaviors and complexities given each cultural background.

According to Gomes, codes can be incorporated and established by undergoing a process of acculturation and can thus promote behaviors arising from a mentality favored in the image one has about oneself, considering the psychological structure that possibly fragments this identity. 
Hall [9] addresses the concept of identity in contemporaneity as a phenomenon associated with plural societies, since this construction is based on the universe of cultural and ideological values and, therefore, of social interests that can change according to the way individuals wish to be represented. In this sense, Hall also postulates on the concept of belonging that is involved in identity politics and diversity when there is a displacement from the national culture.

The identity displacement that Hall refers to, when confronted by readings about Brazilian women, mostly black, considering the whole historical, social and economic context, points towards strong evidence of identity fragmentation and disarticulation. Since the hybrid reality of Brazil has not yet been solved from the sociological and psychological perspective, there is a paradigm that needs to be broken, deconstructed not only in the social realm, but also in the psychological and subjective field.

\subsection{Black Women in the Age of Technology}

The advent of the technological and digital age has led to female insecurity due to women's historical trajectory in society, since dealing with technology requires significant changes associated with acquiring new skills and knowledge, as well as new forms of relating and communicating with other people. In this age, people are "free" to think about their plans in life and their identity, which could lead to a condition of uncertainty [14].

For the woman of color, who has historically belonged to lower classes, the use of technology has broken barriers and created alternative ways of dealing with new knowledge in a social dimension. Kozinets [15] emphasizes the need to understand that technology does not determine culture; rather, both are co-constructive and co-destructive, i.e. our culture is defined by social standards and shaped by technology.

There have been many studies in recent decades about the mobilization of black women into the tech labor market. The impact of this incorporation resulted in a resistance movement that could directly be involved in the deconstruction of racialized and sexist discourses and may lead to changes that pave the way for technological production by black women [5].

Hall [9] postulates that these changes fragment cultural landscapes of class, gender, sexuality, ethnicity, race and nationality that, in the past, had seemed solid. It is relevant to understand that the changes arising from the advent of the tech era have steered events of procedural reconfigurations. Thus, new foundations have emerged and structured alternate outlooks and interpretations of the world. New elements arise for the reinterpretation of the black woman in Brazil and the formalization of important facts gain new interpretations and new identities.

From this point of view, it is possible to find historical factors, in Brazil, that have undergone significant influence as a result of the advent of the tech era, such as the integration of the black woman into the business market as a producer and her (albeit slowly) increasing visibility, which reconfigure new forms of consciousness in respect to diversity.

According to the Baobá Portal [16], there are a small but significant number of black women represented by their ideas and creations in the fields of science, technology and engineering, paving an expressive path towards labor market inclusion. Participation of black women in computing is still minor, accounting for only $4 \%$ of female founders of tech startups, and only 10 black women have graduated from the leading university (Universidade de São Paulo - USP) Polytechnic School in a period of 120 years [17].

With regards to remuneration, black women are also in disadvantage, as their income is $40 \%$ lower than their white male counterparts [18]. The situation is no different abroad: In the United States [19], African-American and Latin women [20] are also a minority in the field [3], including participation in technology contests (such as hackathons and programming competitions) [21], and they earn the lowest wages.

The advances considered in this study derive from a historical process of affirmative struggles and image reassessment assigned to black women that denote the emergence, in the tech era, of a sophisticated and propitious approach that is capable of implementing a needed measure of quality for a marginalized class and that employs novelties in technology as a form of resistance [14]. The complexity entailing different and volatile outlooks highlights the importance of critical studies that are appropriate for this liquid and fleeting time, and new codes and techniques present challenges against conventional ways of viewing and interpreting the world.

\section{Women in Computing and Technology}

Considering the trajectory, albeit an incipient one, of black women as the producer of technology, perhaps gender discussions concerning the access to computing function as a bridge to understand new identity demands in the labor 
market. There is a clear need to improve understanding of this underrepresented group within computing - a field that is in urgent need of more skilled workers, including minorities such as black women [2].

Many social groups and computer science associations, such as Computing Research Association (www.cra.org), Anita Borg Institute for Women and Technology (http://anitaborg.org) and IEEE Computer Society (www.computer.org), recognize that black women face unique challenges such as isolation, lack of confidence, and work overload, both in the academic realm and the computer industry. They propose a few successful strategies for overcoming these problems [3]: (i) creation of mentoring networks and support for black women in the fields of technology; (ii) dissemination of role models; and (iii) recognition of cultural diversity in technological production.

Thus, initiatives emerge in both Brazil and abroad to practice these strategies. The following subsections present a synthesis of these initiatives around the world, considering their cultural, technical and performance peculiarities.

The methodology adopted for building the summary of strategies included in this article undertakes a qualitative netnographic approach and employs the French Model of Discourse Analysis as a tool [22]. The research fields used in this study include social networks (Facebook and Instagram) that disseminate the initiatives of black women who consume and produce networked technology.

The methodology herein adopted is the Discourse Analysis of Images (in this case, logos of black women's initiatives in Computing). The analysis takes as a starting point the visual statements in the logo of each initiative considering the historical and image route reproduced by media and the intentionality of the message attributed there to the readers. The interpretation of the phrases in each logo adopts as criteria the following elements: ideological formation, context, subject, meaning, memory, conceptions of production and discursive formation.

\subsection{Initiatives Abroad}

- $\quad$ Black Women in Computing (BWiC - http://blackwomenincomputing.org/): A community created in the United States to provide support and resources with the aim of increasing the number of black women and other underrepresented groups in computer science and related fields. BWiC emerged at the "GHC2010 Women of Color" meeting with the panel "Building Our Community: Moving Vision into Reality" and was launched in 2011 during the Grace Hopper Conference with help from the Anita Borg Institute for Women and Technology in the session "Black Women in Computing: Increasing Numbers Through Networking".

$\mathrm{BWiC}$ joins efforts in recruiting and retaining black women in computer sciences fields, providing free online resources, offering them national and local support, and publicizing actions held in black, Latino and other minority communities.

Figure 1 shows that black aesthetics (represented by the profile of a black woman wearing an afro, with illustrations representing technology depicted in her head and hair) are used to sediment a historical identity shift from invisibility to visibility, which is beyond representation, since the aesthetics represent its essence, insofar as it communicates its significant function that, from the point of view of ethnology, responds to what is sought of it $[22]$.

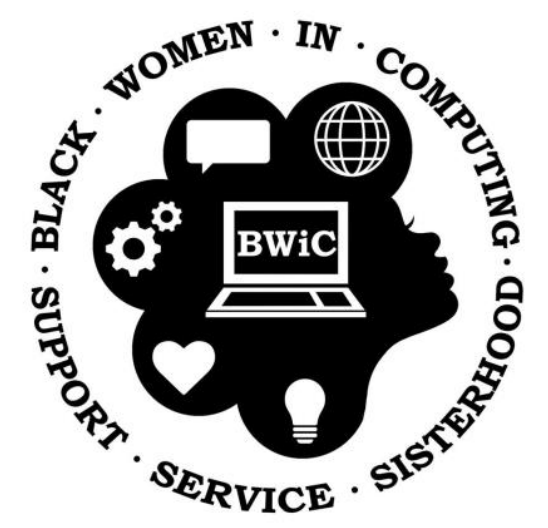

Figure 1: Aesthetics of the identity of the techie black woman are represented by the BWiC logo. 
Pêcheux [23] states that the observation of the elements that determine meaning reveals the embedded discourses. By analyzing the material aspects that guide and ground usual actions and behaviors, it is possible to explain how human thought is being executed at a given time. Therefore, the order of discourse undertaken here indicates not only black identity, but also the quest for self-affirmation and greater visibility in the struggle.

Frantz Fanon [12], a black identity theorist, would say that the image represented in Figure 1 demonstrates a process that seeks the foundations established by the image that depicts the black woman in her central role inherent to overcoming a socially imposed condition in a process of transition from this condition to social self-affirmation. In this sense, liberation from a stereotyped image is contingent upon the black woman's struggle to be validated by her actions. Under this condition, Fanon states that the behavior regarding her aesthetics has only been possible due to the reflected act that prepares her for action.

- Black Girls Code (www.blackgirlscode.com): A community from the United States dedicated to showing the world that black girls can program and build technology together. The community is structured into workshops and school programs, targeted at black girls and other minorities, for teaching robotics and computer programming with languages such as Scratch and Ruby on Rails. It aims to train more than 1 million black girls by 2040 through these actions and thus increase the number of black women in the tech market.

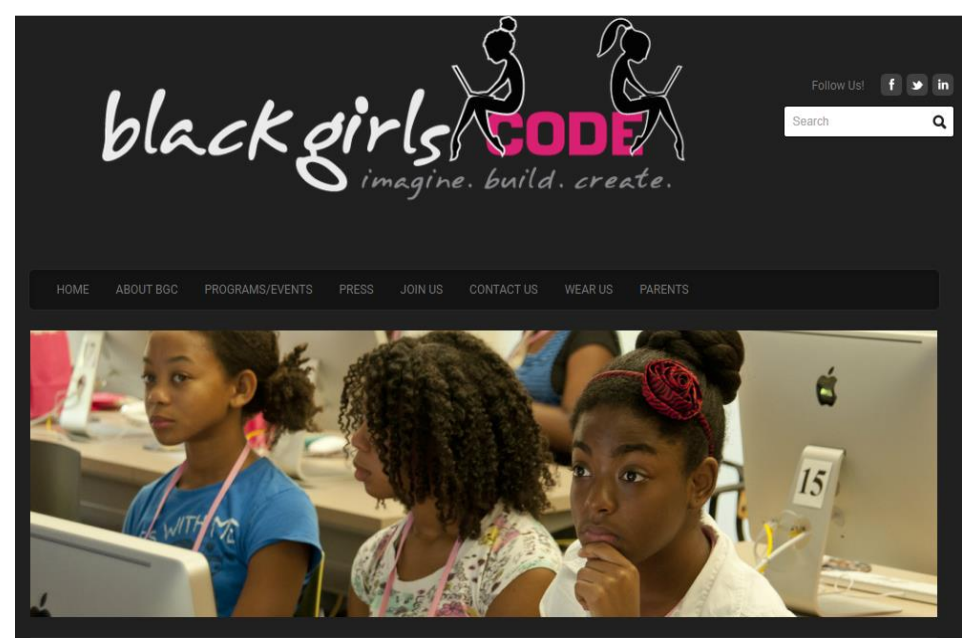

Figure 2: Representation of black girls can be observed in the aesthetics of the Black Girls Code webpage.

Figure 2 depicts important materiality factors of image predominance of female and racial affirmation that the logo discloses, parting from the observation of the object in its social and cultural context, which reasserts these objects in the articulation of image struggle. In this sense, the unfolding elements that give meaning to the aesthetics of the signs also disseminate the imagery language that aggregates senses and has correlations with resistance dynamics [24].

- Black Tech Women (http://blacktechwomen.strikingly.com): A United States community whose aim is to hold events and connect black women working with technology. The community is centered on three pillars: connecting black women across the country; sharing the voice of the black woman, her experiences and perspectives; and creating opportunities for connection through participation in events and job opportunities. Elements of power in black aesthetics are developed in community events for encouraging leadership roles for black women in the field, as can be observed in Figure 3. 

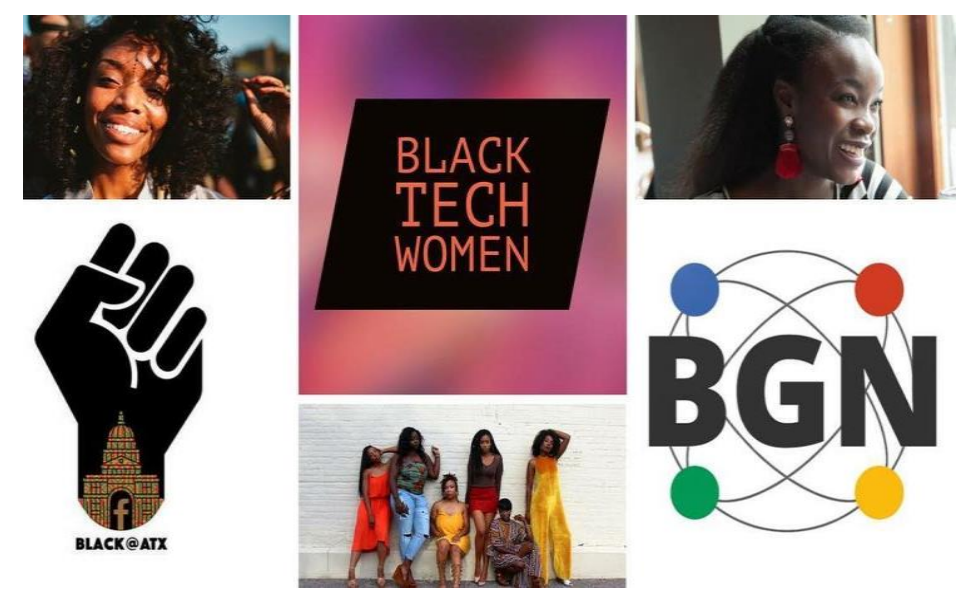

Figure 3: Images of the Black Tech Women social network.

The six images presented in Figure 3 not only render visibility to the black aesthetic, but also disseminate the act of reassigning meaning to the female presence as an intentional object of promoting image writing, while connecting important aspects such as art, technology, politics and human being, whose sense of moral responsibility appears in authentic protest against any type of discrimination. Knowing that this discrimination is visual due to the black body, the body logic described in four elements in the images generates effects and meanings as the social memory operator that reports countless struggles for the recognition of this black body as a human being [23].

- Black Women Talk Tech (www.blackwomentalktech.com/events): an annual event held in the United States that aims to share knowledge and resources and help black women build leading tech companies. The event seeks not only to include black women in technological production, but also elevate these women to positions of leadership and power by creating their own companies. Role models and sororities of black women are highlighted in the aesthetics of the website, as depicted in Figure 4.
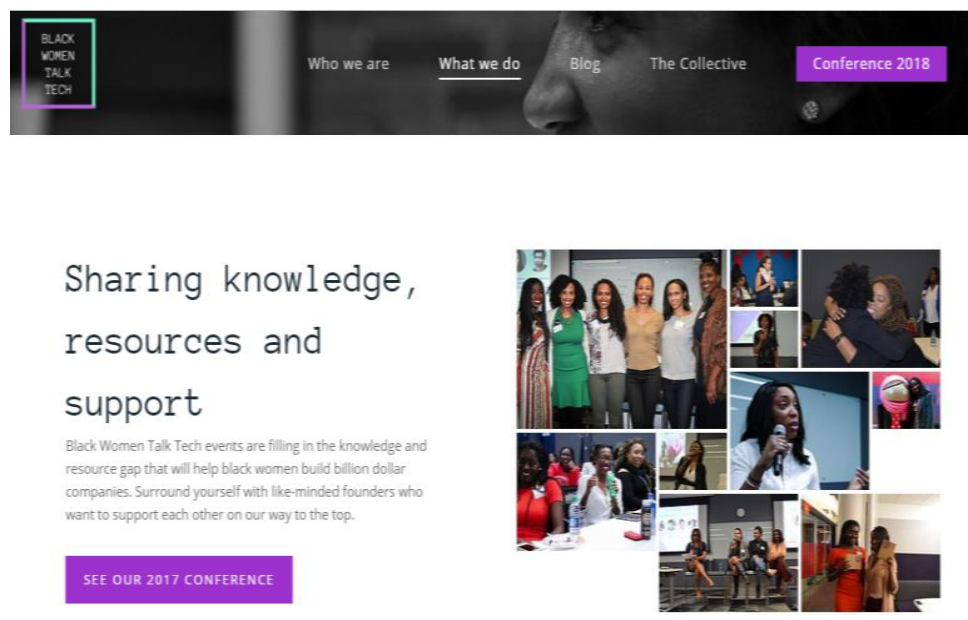

Figure 4: Website of the Black Women Talk Tech event.

- $\quad$ Tech Needs Girls (www.facebook.com/techneedsgirlsgh): movement and mentorship program created by Soronko Academy (www.soronkoacademy.com), from Gana, in order to increase the number of women and girls in creating technology. Its mission is mentoring women and girls to become leaders and innovate through computer programming. 
Tech Needs Girls has already aided more than 4,500 black women and girls, including girls living in the outskirts of towns, in order to guarantee their access to university and prevent them from being forced into marriage. Figure 5 presents a photograph of the girls served by the movement, proudly displaying their course completion certificates.

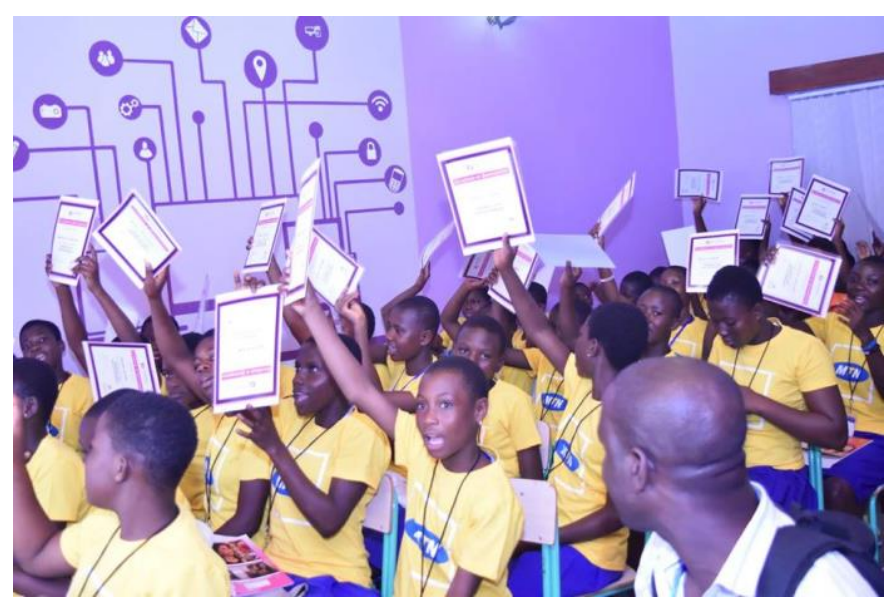

Figure 5: Girls participating in Tech Needs Girls.

- $\quad$ Ms. Geek Africa (www.girlsinict.rw/msgeekafrica2018): competition held in Rwanda for young African women, aged 13 to 25 , which seeks to encourage them to show their skills and knowledge in Information Technology. The girls participate in groups of five with ideas for apps to solve a problem they have experienced. The finalists win an intensive computer programming and entrepreneurship course and the winners receive prizes in cash and tech products.

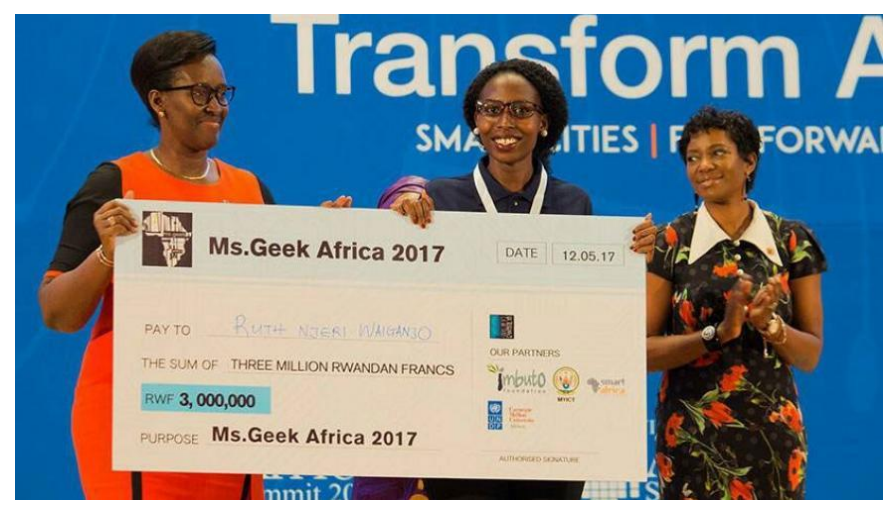

Figure 6: Winners of Ms. Geek Africa 2017 [25].

Figure 6 shows the winners of Ms. Geek Africa 2017 holding their prize. The event demystifies the negative image of the term geek, equating it with a sense of hard work, success and transformation associated with the image of African woman.

- Latin American women: As for Latin America, it is possible to find a few initiatives that address issues related to the Latin American woman in technology, such as Latinas in Computing (http://latinasincomputing.org/about), Technolochicas (https://technolochicas.org), Latinas in Tech (www.latinasintech.org), PionerasDev (http://pionerasdev.co/nosotras), the LATINITY events (http://latinity.co) and the Conference of Latin American Women in Computing (http://cleilaclo2018.mackenzie.br/lawcc). However, there is little visibility of the empowerment of black and Latina women, with actions geared towards Latinas in general. In Brazil, it is possible to find initiatives 
that are dedicated to black women in this field and its specificity. The Brazilian initiatives tailored to black women in technology will be highlighted in the following subsection.

\subsection{Initiatives in Brazil}

- $\quad$ Programa Meninas Digitais (Digital Girls Program - http://meninas.sbc.org.br) and Meninas Digitais Regional Bahia (Digital Girls Program - Bahia - http://meninasdigitais.ufba.br): The Digital Girls Program of the Brazilian Computer Society (SBC - www.sbc.org.br/) aims to publicize the computer science and computer technology to arouse the interest of middle school, high school and technical school students, so that they become more familiar with the topic and are consequently motivated to pursue a career in computing [26, 27]. The Digital Girls Program benefits from the collaboration of so-called multipliers, who execute partner projects in their own institutions, in order to disseminate this idea throughout the country.

Many of the program's partner projects develop actions from/to black girls. A primary example is the project Digital Girls Regional Bahia, which seeks to include girls who are either black or public school students from the northeastern state of Bahia, as a means of creating opportunities for these minorities to have contact with science and technology. The project conducts lectures and workshops in public schools and researches about black women in science and computing [28].

The logo of the Digital Girls - Regional Bahia program, illustrated in Figure 7, depicts a black girl with an afro hairdo, which consists of digital circuits in colors of the rainbow, thus also representing women identifying themselves as LGBTQ+ (lesbian, gay, bisexual, transgender, queer, and other gender identities). Bahia is ranked third among the state with the greatest number of homicides against and suicides of the LGBTQ+ community, and this number rose 30\% between the years of 2016 and 2017 [29]. For black LGBTQ+ women, the project presents itself as a safe space for networking and training in the region.

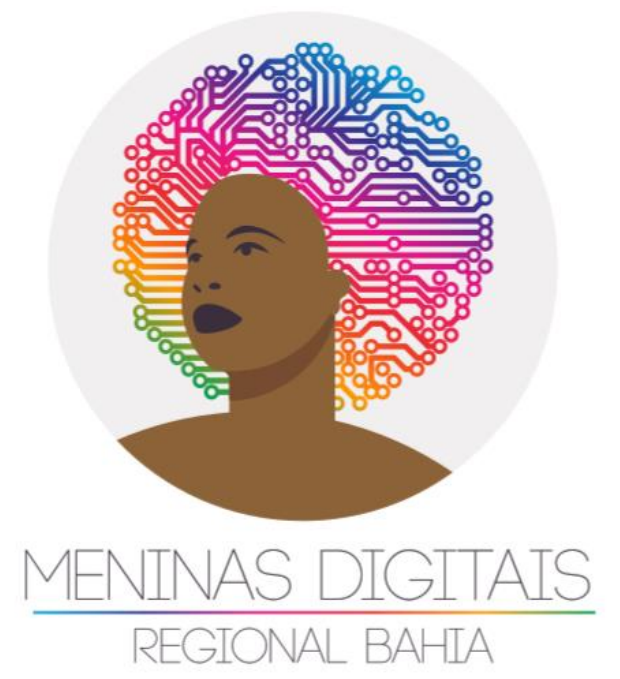

Figure 7: Logo of the Digital Girls - Bahia project.

In this sense, it is observed that the black diaspora is represented by the image of the hair and African ancestry since, according to Gomes [30], hair manipulation is a memory deposit, based on the concept that a person's hair, according to the tradition of each ethnic group, has the function of communicating something subjective or cultural with great symbolic force. In Figure 7, the logo of the project communicates this symbolic force through representation of the hair and black skin, rendering new meaning and re-creation from a historical construction of struggle for social self-assertion.

The discourse in this image presents a "relation" that reveals the revolutionary sentiment of liberation and struggle towards the identity of the black woman elaborated as a manifesto, which Courtine [31] describes as inter- 
iconicity, when the image assumes the relation of the internal with the external, even in the imaginary realm; that is, every image ascribes the individual's existence through a visual memory that remembers other already seen images.

Thus, it is verified that the imagine-related dialogue explicitly addressed in this logo belongs to a tangle of formulations that the designer who created the image may have used in the midst of her memorized experiences, introducing the background of the illustrated woman, not only through the color of her skin, but mainly by her hair merging with their own imaginary inquiries of their own history in the Brazilian context and with unconscious universes of values acquired from and through an experience with Africanness - a very strong trait in Bahia.

- InfoPreta (www.infopreta.com.br): Brazilian company with a social vision created in 2015 exclusively by black women. Their mission includes propelling women (who are black or from other minorities) to the exact sciences and helping protect the environment through the adequate disposal of electronic waste and other materials. Preta means black in Portuguese. InfoPreta offers technical restoration services, maintenance and assembly of computers. It also offers to recycle notebooks, desktops and electronic devices in general, which are donated to women who live in the outskirts, in the "Project Black Solidary Notebooks", depicted in Figure 8.

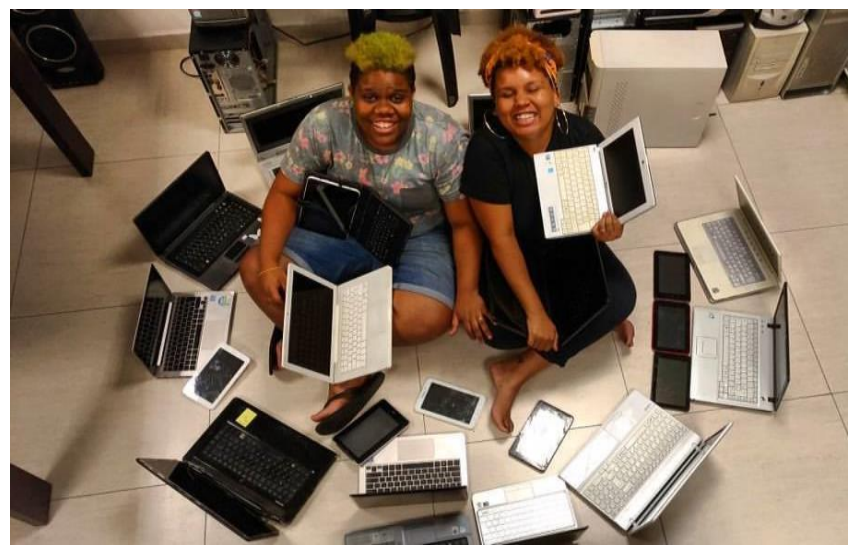

Figure 8: Project Black Solidary Notes, photo from InfoPreta social media.

Another social project by InfoPreta is "Black Rehabilitation", which seeks to employ black women who are homeless and former inmates. More than $68 \%$ of the Brazilian female penitentiary system are black women, aged 29 years or less, who have not yet completed middle school, some of whom are still illiterate [32]. The project includes courses and scholarships for these women; moreover, it offers lectures and courses in technology, innovation and entrepreneurship, with a focus on ethno-racial relations, gender and diversity. The company has a partnership with Microsoft Brazil and was recently selected to represent Brazil in the G20 in Berlin.

- Minas Programam (Girls in Programming - http://minasprogramam.com): a project that seeks to deconstruct the idea that men are more capable at programming than women, by means of sharing technical and political knowledge. The project promotes a basic training space, for women who want to learn more about programming but do not know where to start, through lectures and courses that also address racial issues such as "Black Meetup", "Black \& Academic" and "WordPretas" (http://minasprogramam.com/wordpretas/ - see Figure 9). The project relies on partnerships with companies in the computer field, such as ThoughtWorks, and publicizes, through media, the stories of black women in the IT field in order to encourage more black women to pursue the field. 


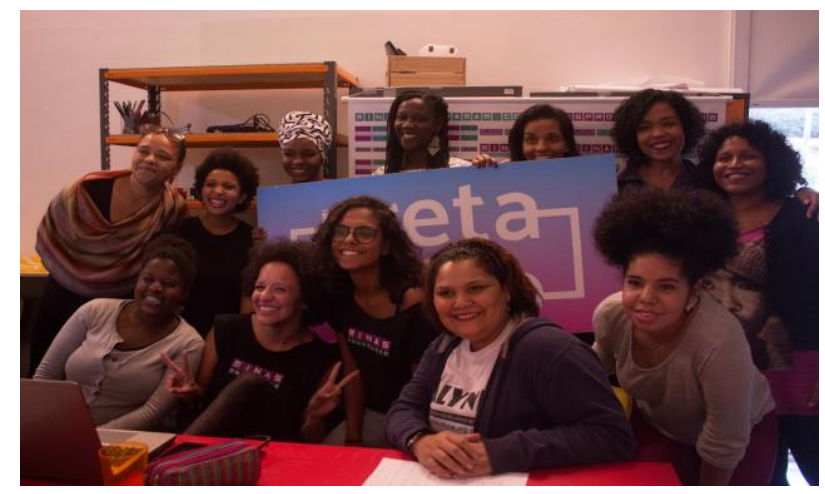

Figure 9: WordPretas conducted by the project Girls in Programming in partnership with PretaLab, photo from PretaLab social media.

- $\quad$ PretaLab (http://pretalab.com): Initiative by Olabi Makerspace with the support of Ford Foundation, which believes in the protagonist role of black and indigenous women in the fields of innovation and technology as a form of reducing social inequality in Brazil. Its goal is to conduct a survey to collect the stories and challenges of black and indigenous women, who work with or are interested in technologies, using a collaborative map to illustrate their trajectories. The idea is to encourage other women to consider the universe of computing as a possibility by expanding the space and representation of these women in the field.

Figures 8 and 9 show that there is a diversity of aesthetics and colors represented by Brazilian black women who use technology as a tool for their struggle and cultural production. Experimental developments enable the reinterpretation of color directly related to an identity shift that, in the beginning of the history of blackness in Brazil, was depersonalized, and is presently given new meaning by dialectical processes that promote equal rights, as formerly male-only spaces begin to be occupied by women in minority status as a form of resistance and selfaffirmation.

It can be noticed that, in these images, the perspectives leaning towards sphericity are also a way of emphasizing the dialectic of the African diaspora that is subscribed to a visual culture and, through it, asserts existential relations, communicates its epistemological reconfigurations from the historical conditions that are attributed to them as representation of the unconscious desires that determine the "place" that people of color occupy in relationships that symbolically call for spherical positions, and which in reality are confronted with the verticality attributed to Caucasians.

It is important to emphasize that the images of this summary seek to pedagogically reconstruct the ontological image of the black woman in an original, creative and poignant way. Before the mirror, there is an unconscious reflection of her quest for the faulty object of her subjectivity, beyond empowerment and self-affirmation. The photos and images of the black woman in present-day technology seek to represent the true existential image of struggle, love, solidarity and sorority of their relations and in the assertion of their posture as humans.

\section{Final Considerations}

Considering the results of the image materiality of the black woman by the technologies and the similarities configured from the presentation of the data obtained in academic literature and in the projects this essay discussed, it was possible to infer an identity self-affirmation and resistance of these women in computing and technology.

There are still no precise statistics about this networked movement, except in several "likes" and "commentaries" that alone reveal the impacts of expressions [33]. It is crucial to highlight that black women's empowerment within virtual movements already denotes behavioral changes, from passive to active, with respect to the rupture with these pre-established models that have historically relegated the black woman to a subordinate plane in Brazil, especially in the mainstream media.

In this movement, there is constant debate around how to combat racism and white hegemony in social sectors. These networks become a means of transmitting black self-affirmation and equality of opportunity for all, as pronounced by the national constitution. 
The common understanding among the authors mentioned in this essay, with the intention of building knowledge in a structural re-composition of non-standardized knowledge, draws attention to knowledge possibilities in written language, which challenge the individual to take a stance of resistance. We are reminded to question what this movement would be like if computing were a ground of resistance that, in addition to knowledge production, can become a political-cultural movement towards new articulations and new identities in the contemporary context.

It follows from the foregoing that the reported analyzes of the relationship between black women and computing comprise an understanding of the specificity of current technology as a language for epistemic knowledge and of the imposing ethno-racial debate that is able to articulate decolonizing image diversity with concepts of otherness and human rights awareness.

The initiatives generally identified in this study as production by black women to black women constitute a theoretical framework that guides the understanding of the discussion about black women as technology producers and their relevance in the contemporary scene. Because it is also a political-cultural element, the study provokes displacements that may deconstruct positions and mono-cultural ideas based on eugenic concepts [34] that were responsible for generating exclusion in the past.

We noticed that innovation and computing areas have encouraged the preparation of black women, who are segregated and marginalized, for acting as producers of technology that is open to cultural plurality and that can generate knowledge that overturns dominant paradigms. The social initiatives in the market, research and development presented in this essay point towards the advancement of discussions in the field and signal at paths for collective work in favor of the intersectional gender equity of computing that also includes the relationship between race and social class. In this sense, it is important to stress the role that institutions, associations, communities and others play in strengthening and supporting these initiatives.

Technological practices as a means of resistance are already a revolutionary reality of otherness and consciousness, because they undertake the guiding thread against domination devices by unmasking oppressive interests and signaling paths of liberation by the black movement that transcends the image of identity selfaffirmation.

From all the considerations highlighted in this paper, it is possible to think of black women in computing in a universe of perspectives, possibilities, exchanges and narrowing of relationships through dialogue and respect for diversity, in short, a space of construction configured by the liberating action of educating for new times, new spaces and new paths.

It is relevant to understand that the changes arising from the advent of the technological era have guided procedural reconfigurations. Therefore, new foundations have emerged, structuring other worldviews and thinking patterns, in which new elements arise and important facts formally acquire new vestments, new interpretations and new identities.

From this point of view, it is possible to point out the importance of a racial discussion in the sphere of computing, in the attempt to understand historical factors concerning Afro-Brazilian women who have suffered significant influence arising from the advent of the technological age and the paths followed in order to gain expressive visibility in the virtual field. Thus, rendering it possible to deconstruct the idea of racial democracy, specifically the image of the Black Woman, by reconfiguring a new conscience in respect to diversity.

In our analysis, we identified ideological materialities that intertwine the places of speech and dialogue with the actors who undertake resistance by recomposing new discourses and reconfiguring new ways of giving visibility to the object throughout the production process.

\section{Acknowledgments}

We would like to thank all the black women who, with incredible force, refuse to allow social constructions to prevent them from being who they want to be and from occupying the spaces they wish to occupy by right. We dedicate this essay to all women who are transforming the image of Computing. To the Digital Girls Program of the Brazilian Computing Society, for being a part of this shift in the Brazilian scenario. Also, in the Latin American context, the actions that have been carried out by the Conference of Latin American Women in Computing deserve special mention. 
We would also like to thank the Graduate Program in Education (PPGE) and the Lab of Studies on Information and Communication Technologies in Education (LeTECE), both in the Federal University of Mato Grosso.

\section{References}

[1] Z. Bauman, Vida Líquida. Rio de Janeiro: Zahar, 2007.

[2] L. J. Charleston et al., "Navigating underrepresented STEM spaces: Experiences of black women in U.S. computing science higher education programs who actualize success". Journal of Diversity in Higher Education, 7(3), pp. 166-176, 2004.

[3] CRA (Computing Research Association) et al., "Academic Women of Color in Computing: A Testimony on the Issues and Possible Solutions", 2002. [Online]. Available: https://www.nap.edu/read/18556/chapter/35

[4] M. M. O. Lobo, K. S. F. M. Ribeiro and C. Maciel, “A Mobilização de Resistência das Mulheres Negras na Computação e Tecnologias", in Proc. $12^{\circ}$ Women in Information Technology (WIT 2018), 1/2018, SBC, 2018.

[5] T. P. Silva, "Tics: A resistência de Mulheres Negras", in Proc. VI Seminário de Pesquisa em Ciência da Informação do PPGCI, Escola de Comunicações e Artes - Universidade de São Paulo, 2017.

[6] M. Paixão, “A Lenda da Modernidade Encantada: por uma crítica ao pensamento social brasileiro sobre as relações raciais e projeto de Estado e Nação". Editora Curitiba, Paraná, 2014.

[7] J. Stone, "Hume on identity: A defense". Philosophical Studies 40.2, pp. 275-282, 1981.

[8] N. L. Gomes, "Educação e identidade negra", Belo Horizonte, POSLIT/CEL, Faculdade de Letras da UFMG, v. 06, n. 09, pp. 38-47, 2002.

[9] S. Hall, A identidade cultural na pós-modernidade. Editora Lamparina, 12a ed., 2015.

[10] IPEA - Instituto de Pesquisa Econômica Aplicada, "Igualdade Racial. Políticas Sociais: acompanhamento e análise”, n. 11, 2005. [Online]. Available: http://www.ipea.gov.br

[11] B. Paes, "Negras na Tecnologia", Blogueiras Negras, 2016. [Online]. Available: http://blogueirasnegras.org/2016/08/25/negras-na-tecnologia/

[12] F. Fanon, Pele Negra Máscaras Brancas. Trad. Renato da Silveira, Salvador: EDUFBA, 2008.

[13] B. Hooks, “Mulheres negras: Moldando a teoria Feminista.”. Revista Brasileira de Ciência Política, nº16. Brasília, pp.193-210, 2015.

[14] Z. Bauman, Globalization: The human consequences. Columbia University Press, 1998.

[15] R. V. Kozinets, Netnografia: Realizando Pesquisa Etnográfica online. Porto Alegre: Penso, 2014.

[16] Baobá, “Tem Mulher negra fazendo tecnologia e inovação sim!”, Portal Baobá, 2017. [Online]. Available: http://baoba.org.br/tem-mulher-negra-fazendo-tecnologia-e-inovacao-sim/

[17] L. Mendes, “Aluna negra e da periferia supera preconceitos para estudar na Poli”, Folha de São Paulo, Educação, 2017. [Online]. Available: https://www1.folha.uol.com.br/educacao/2017/02/1855107-aluna-negrae-da-periferia-supera-preconceitos-para-estudar-na-poli.shtml

[18] L. S. Pinheiro, A. T. Lima Junior, N. D. O. Fontoura e R. D. Silva, "Mulheres e trabalho: breve análise do período 2004-2014", IPEA, 2016.

[19] The Lily News, "The pay gap is worse for black women. Here's a look at the statistics.”, 2017. [Online]. Available: www.thelily.com/the-pay-gap-is-worse-for-black-women-heres-a-look-at-the-statistics/

[20] S. Kantengwa, "Ms Geek Africa winner on her project and future plans", The New Times, 2017. [Online]. Available: http://www.newtimes.co.rw/section/read/212625

[21] G. Mone, "Bias in technology", Communications of the ACM, 60, pp.19-20, 2016.

[22] K. Munanga, “A Dimensão estetica na arte negro-africana tradicional”, USP- MAC Noticias, São Paulo, 2006. 
[23] M. Pêcheux and E. P. Orlandi, Semântica e discurso: uma crítica à afirmação do óbvio. Editora da UNICAMP, 1995.

[24] M. M. LOBO, "Cinema Negro na Educação: As materialidade da imagem de autoafirmaçao no processo de descolonização”, Dissertação de Mestrado em Educação, UFMT, 2017.

[25] L. Souto. "Assassinatos de LGBT crescem 30\% entre 2016 e 2017, segundo relatório", O Globo, 2018. [Online]. Available: https://oglobo.globo.com/sociedade/assassinatos-de-lgbt-crescem-30-entre-2016-2017segundo-relatorio-22295785

[26] S. Bim, K. S. Figueiredo, C. Maciel, "Por Mulheres na Computação no Brasil: análise das ações e publicações do evento Women in Information Technology", in Proc. Congreso de la Mujer Latinoamericana en Computación (LAWCC), XLIII CLEI - 46 JAIIO, ISSN 1850-2776, pp.36-43, 2017.

[27] C. Maciel, S. A. Bim, and K. S. Figueiredo, "Digital girls program: disseminating computer science to girls in Brazil", in Proc. of the 1st International Workshop on Gender Equality in Software Engineering (GE '18). ACM, New York, NY, USA, pp. 29-32, 2018. [Online]. Available: https://doi.org/10.1145/3195570.3195574

[28] E. S. Matos et al., "Sobre a trajetória de professoras negras na pós-graduação em Ciência da Computação: alguns resultados preliminares", in Proc. 10 Women in Information Technology (WIT 2016), 1/2016, SBC, 2016.

[29] L. S. Castro and K. C. Ehrenberg, "O empoderamento de mulheres negras nas redes sociais digitais", LinkedIn, 2017. [Online]. Available: https://pt.linkedin.com/pulse/o-empoderamento-de-mulheres-negras-nasredes-sociais-digitais-castro

[30] N. L. GOMES, “Negra e educação”, Revista Brasileira de Educação, Maio/Jun/Jul/Ago, No $23,2003$.

[31] J. Courtine, “Análise do discurso político. O discurso comunista endereçado aos cristãos”, Trad. Vanice Sargentini (org.). São Carlos, SP: EdUFSCar, 2009.

[32] InfoPreta, "Projeto Social”. [Online]. Available: https://www.infopreta.com.br/projeto-social/

[33] Olabi Team, "A survey about the necessity and pertinence of including more black women in innovation and technology”, PretaLab, 2018. [Online]. Available: https://www.pretalab.com/en/home

[34] N. L. Stepan, A Hora da Eugenia: raça, gênero e nação na América Latina. Rio de Janeiro: Editora Fiocruz, 2005. 